Research Article

\title{
Research on the Reinforcement Mechanism and Safety Monitoring of Heavy-Duty Concrete-Encased CFST Columns
}

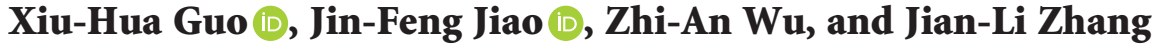 \\ College of Civil Engineering, Taiyuan University of Technology, Taiyuan 030024, China \\ Correspondence should be addressed to Jin-Feng Jiao; jiaojf_1@126.com
}

Received 16 September 2019; Accepted 17 December 2019; Published 24 January 2020

Academic Editor: Emanuele Brunesi

Copyright (c) 2020 Xiu-Hua Guo et al. This is an open access article distributed under the Creative Commons Attribution License, which permits unrestricted use, distribution, and reproduction in any medium, provided the original work is properly cited.

\begin{abstract}
With the reinforcement project of a heavy-duty concrete-encased concrete-filled steel tube (CFST) column as the background, the mechanism of column reinforcement with supporting beams is proposed. The key mechanisms include the following: (1) designing the upper and lower corbel-shaped temporary support columns, (2) crack repairing the inner steel pipe using patch-shaped steel plates, and (3) replacing microwound concrete inside the steel pipe, which are all innovative and effective methods. Moreover, a system is developed for monitoring the safety during the reinforcement process and recovering the bearing capacity of the concrete-encased CFST column. The monitoring results indicate that the load conversion process of the temporary support columns lasts for 50 days, that the sum of the axial forces of the four supporting columns is $7,966.0 \mathrm{kN}$, accounting for $65 \%$ of the standard load, and that during the whole process, the structural components are safe and reliable. Finally, the construction simulation is in agreement with the field test results, which proves that the construction simulation developed based on the theory of slow time-dependent mechanics and the method of static nonlinear analysis is accurate.
\end{abstract}

\section{Introduction}

Concrete-encased concrete-filled steel tube (CFST) columns are a type of composite structure composed of an inner CFST component and outer reinforced concrete. This type of column is increasingly being applied to high-rise and superhigh-rise buildings in China. Compared with the concretefilled steel tube columns, the local buckling model of the steel tube in concrete-encased CFST columns is improved due to the protection of the external reinforced concrete. Compared with the reinforced concrete columns, concreteencased CFST columns have better seismic and fire resistance $[1,2]$. Structural construction monitoring and safety assessment are deployed to use the on-site nondestructive sensing technology to monitor the overall behavior of components in real time. The service conditions, carrying capacity, and reliability of the structure are intelligently evaluated, and an early warning signal will be sent when an emergency occurs or when the construction condition is severely abnormal. Construction monitoring can provide the basis for structural construction safety, progress, and management decisions $[3,4]$.

An and Han conducted an experimental study on the performance of a concrete-encased CFST column under combined compression and bending. In their study, they proposed a failure model and a simplified finite element analysis (FEA) model [5]. The torque-rotation angle relation of the concrete-encased CFST columns under combined compression and torsion loads was also investigated by Ren et al. [6]. In the context of the frost cracking of concrete-filled steel tube columns in main factory building, the cause of frost cracking, reinforcement schemes, and safeguard measures were analyzed and summarized [7]. In addition, for the problem of the inconsistency and the insufficient strength of the concrete-filled steel tube column in a high-rise building, Yuan et al. introduced the reinforcement method and process of local concrete replacement [8]. In another work, to ensure the safety of the cutting process of a steel platform beam subjected to equipment load in a 
manufacturing workshop, Song et al. studied the cutting process through FEA and health monitoring using fiber brag grating (FBG) sensors [9]. Yang et al. carried out construction monitoring on the steel roof of Yancheng Nanyang Airport, which showed that the roof steel structure was in an elastic stage during the construction process and the structure was safe [10]. Xu et al. described the top-down method, the continuous wall retaining system, and the long-term monitoring program for the deep excavation of the Shanghai Center [11]. Xiong et al. proposed that a novel subregional least squares method should be used to calculate the horizontal displacement of frame-core-tube structures with strengthened stories [12]. Furthermore, Su et al. reported a settlement monitoring approach based on the Kalman filter, which has been demonstrated to improve the accuracy of the predetermined elevation of supertall buildings through construction settlement monitoring of the 632-meter-tall Shanghai Tower [13].

Although the design level, construction technology, management, and engineering have continuously been improved over time, currently, little relevant information or research is available on the quality damage and reinforcement engineering of concrete-encased CFST columns. Based on the reinforcement of a heavy-duty concreteencased CFST column in a frame-core wall structure, the research presented herein proposes the key advanced mechanism of column reinforcement by supporting beams and designs a safety monitoring system for reinforcement construction and bearing capacity recovery. The construction simulation was developed based on the theory of slow time-dependent mechanics and the method of static nonlinear analysis. Through the simulation and construction monitoring, the mechanical behavior and the deformation rule of the structural components can effectively be obtained, which provides a theoretical and practical basis for the safety assessment during the construction and the future rational use of the concreteencased CFST columns and offers a critical reference value for similar projects.

\section{Engineering Situations}

The structure type of a tall building used in the current study is the frame-core wall structure, and the surrounding frame is a concrete-encased CFST column. The seismic precautionary intensity of the building site is also $8^{\circ}$. The building has 34 stories, with a story height of $3.8 \mathrm{~m}$ and a standard layer of $52.8 \mathrm{~m}$ in length and $24.0 \mathrm{~m}$ in width. The standard floor plan is presented in Figure 1(a). The main structure of this building was completed in 2016 and has not been renovated. A year later, column 5 of the $15^{\text {th }}$ to $18^{\text {th }}$ floor of the building suffered some damage, and some vertical cracks appeared on the surface of the columns; column 5 of the $15^{\text {th }}$ floor was severely damaged.

Column 5 of the $15^{\text {th }}$ to $18^{\text {th }}$ floor is a concrete-encased CFST column with a cross section depicted in Figure 1(b). The inner steel pipe is a $\varnothing 900 \times 36$ Q345 steel pipe; the outer part is reinforced concrete, with an outer diameter of $1,400 \mathrm{~mm}$, in which $32 \times 32$ longitudinal rebars made of HRB400 material are arranged. A ring beam with a radial thickness of $500 \mathrm{~mm}$ and a height of $900 \mathrm{~mm}$ is set up at the intersection of the CFST composite column and the frame beam; the section of the frame beam is $500 \mathrm{~mm} \times 800 \mathrm{~mm}$, and the thickness of the floor plate is $120 \mathrm{~mm}$. The concrete strength grade of all the components is C40.

2.1. Accident Cause Analysis. Column 5 of the $15^{\text {th }}$ floor was seriously damaged; in fact, five vertical cracks were created on the surface of the outer reinforced concrete from the elevation of $0.85 \mathrm{~m}$ to $2.40 \mathrm{~m}$ in a horizontal angle range of $270^{\circ}-360^{\circ}$; the angle is defined as shown in Figure 1(b), with the south direction being $270^{\circ}$ and the east direction being $360^{\circ}$. The five vertical cracks were of a penetrating type, reaching a length of about $1.0 \mathrm{~m}$ and a maximum width of about $4.5 \mathrm{~mm}$; the longitudinal rebars were also bent at the corresponding positions. After chiseling the column, it was found out that the inner steel pipe was also cracked in the vertical direction at the corresponding positions. The length and the maximum width of the crack were, respectively, about $1.50 \mathrm{~m}$ and $10.0 \mathrm{~mm}$, and the surface of the steel pipe laterally bulged out convexly. The concrete inside the steel pipe was relatively humid, and substances such as segregated water, mud, and discrete aggregates were seen at the locations. The damage to the inner steel tube is schematically illustrated in Figure 2.

The accident was caused by the frost heaving of the internal concrete. After the internal concrete is condensed, the excess free water will accumulate within a certain range. When the accumulated water reaches a certain level, it freezes at low temperatures in winter, which causes the concrete inside the steel pipe to swell. Consequently, the circumferential tensile stress on the steel pipe increases and reaches the yield stress of the steel pipe in winter. Then, the steel pipe begins to plastically deform and bulges out at the stress location. On the contrary, steel becomes brittle as temperature decreases, which means that its plastic deformation ability is greatly reduced. Therefore, the deformation of the steel owing to lower ductility at low temperatures is limited, and a brittle fracture failure occurs when the steel pipe is unable to withstand the circumferential tensile stress generated by the significant expansion of the internal concrete.

2.2. Design and Construction of Key Mechanisms of Reinforcement. The replacement concrete method was employed to reinforce the damaged concrete in the steel pipe, and the steel pipe cracking was repaired by welding a steel plate on the outer surface of the pipe at the crack position. A reinforced-concrete temporary support system was designed around column 5 on the $13^{\text {th }}-18^{\text {th }}$ floor to realize the partial unloading or the load conversion of the original column 5 . Then, the column reinforcement with supporting beams was carried out for column 5 on the $15^{\text {th }}$ floor. 


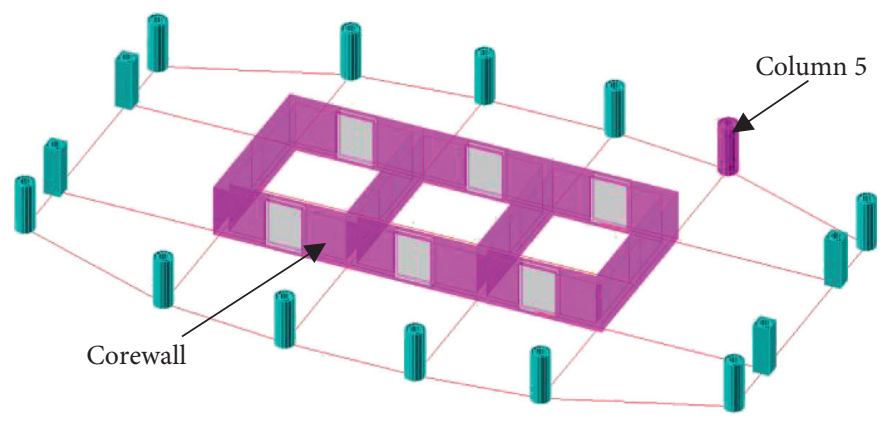

(a)

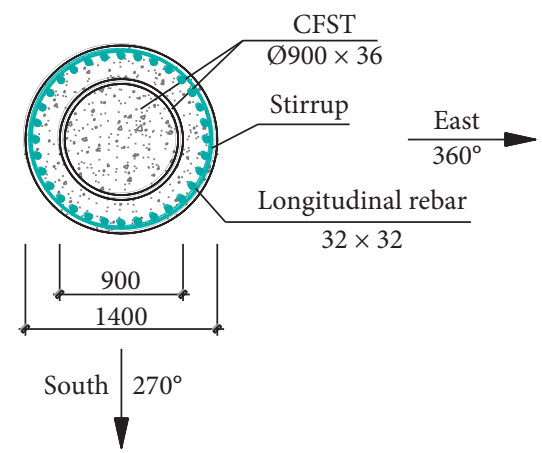

(b)

Figure 1: (a) Standard floor plan and (b) column 5 section on the $15^{\text {th }}$ floor (unit: $\mathrm{mm}$ ).

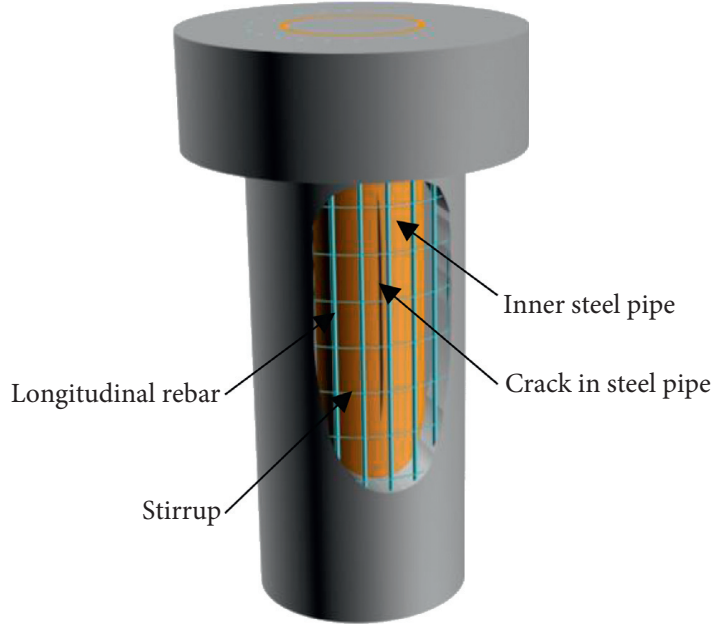

FIGURE 2: Crack in the inner steel pipe of column 5 on the $15^{\text {th }}$ floor.

2.2.1. Design of Temporary Support Columns. The tall building has a total of 34 floors, and the destroyed columns are column 5 on the $15^{\text {th }}$ to $18^{\text {th }}$ floor. During the reinforcement construction, load of the original composite column 5 should be transferred to some temporary support columns. The standard load on column 5 on the $15^{\text {th }}$ floor is $12,230.0 \mathrm{kN}$, which is calculated according to the existing dead load (including the concrete filled in the steel pipe) and the live load of $0.5 \mathrm{kN} / \mathrm{m}^{2}$ per floor. The column is subjected to a large load, and it is difficult to unload it; thus, the design of the temporary support columns is proposed as shown in Figure 3.

Firstly, three temporary jacking devices were installed between the frame beams on the west, east, and south sides of column 5 on the $15^{\text {th }}$ floor. There was no device on the north side of the column because of the cantilevered frame beam. The main component of the device was a steel column, whose top and bottom were then provided with connecting steel plates, respectively. Subsequently, a jack was installed between the upper connecting plate and the upper frame beam, and a steel wedge was embedded between the lower connecting plate and the lower frame beam to provide support. Thus, the temporary jacking of column

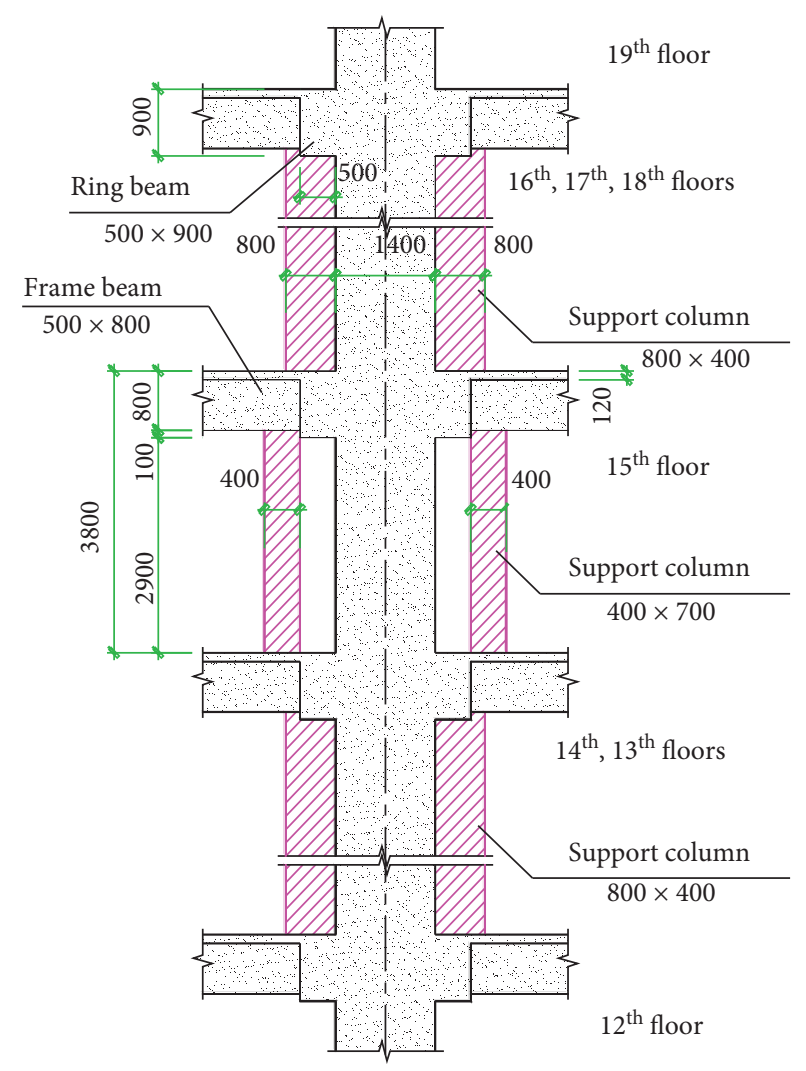

Figure 3: Design of temporary support columns.

5 was achieved with the devices. Under the support of the temporary jacking devices, the reinforced concrete temporary support column system was established as follows.

For column 5 on the $13^{\text {th }}-18^{\text {th }}$ floor, the temporary support columns made of reinforced concrete were set up, as presented in Figure 3. Relative to column 5, the temporary reinforced concrete support column was more lateral than the temporary steel column. Four temporary support columns were set up around column 5 on the $15^{\text {th }}$ floor. The support columns and the original column were designed to be independent of each other. The center-to-center distance between the support column and the original column was $1,400 \mathrm{~mm}$, and the clearance between them was $500 \mathrm{~mm}$. The 
cross section of the east, south, and west support columns was $400 \mathrm{~mm} \times 700 \mathrm{~mm}$, and that of the north one was $500 \mathrm{~mm} \times 600 \mathrm{~mm}$; the frame beam was also $500 \mathrm{~mm}$ wide. The support columns were equipped with $10 \times 18$ longitudinal rebars embedded in microexpansion injected concrete with a strength grade of C60. The bearing capacity of the support columns and the partial pressure bearing capacity of the column top section met the calculated load requirements. Moreover, the longitudinal rebars were anchored in two ways in the support columns: (1) the longitudinal rebars in the beam range were anchored by implanting the beam to a depth of $300 \mathrm{~mm}$; (2) the longitudinal rebars in the floor range were anchored by the anchor bolts penetrated into the floor. Four support columns with a section size of $800 \mathrm{~mm} \times 400 \mathrm{~mm}$ were also designed and placed identically on the $13^{\text {th }}, 14^{\text {th }}$, and $16^{\text {th }}$ to $18^{\text {th }}$ floor. The support columns were connected to the original column using alloy steel grade M20 8.8 anchor bolts. There are three anchor bolts in a row in each column, and the vertical spacing between the rows is $200 \mathrm{~mm}$.

The temporary support column was rooted on the ring beams and the frame beam, which was equivalent to attaching a corbel with a height of $8.5 \mathrm{~m}$ to the original column 5 below the $15^{\text {th }}$ floor and a corbel with a height of $12.3 \mathrm{~m}$ to the original column 5 above the $15^{\text {th }}$ floor. Four support columns and four corbels surrounded column 5, and the temporary support columns on the $15^{\text {th }}$ floor were placed between the upper and lower corbels. This arrangement was called the upper and lower corbel-shaped temporary support column design.

When the concrete strength of the temporary reinforced concrete support columns reached the requirements, the temporary jacking devices were removed. Because the steel columns are relatively flexible, their axial forces are small, and they are not fixedly connected to the original structure, and three steel columns were removed within 1 day. The removal order of steel columns was as follows: western steel column, eastern steel column, and southern steel column. Then, the temporary reinforced concrete support columns undertook the unloading work of column 5 until its reinforcement construction was completed.

\subsubsection{Real-Time Monitoring of Stress and Displacement.} The seriously damaged column 5 on the $15^{\text {th }}$ floor displays the characteristics of a heavy load, complicated forces, difficult unloading, etc. In order to ensure reinforcement construction, it is necessary to carry out the health monitoring and safety assessment of the construction process and the bearing capacity recovery of column 5 on the $15^{\text {th }}$ floor in real time. The monitoring elements included the following: (1) assessing the variation of the layer height near column 5 on the $15^{\text {th }}$ floor, as well as monitoring the stress variation of the four temporary support columns during the reinforcement construction process; (2) assessing the variation of the layer height near column 5 along with analyzing the stress recovery of column 5 continually after the reinforcement construction was completed.

\subsubsection{Column Reinforcement by the Supporting Beams.} For column 5 on the $15^{\text {th }}$ floor, the construction process of column reinforcement with supporting beams is as follows: creating the temporary support columns on the $13^{\text {th }}$ to $18^{\text {th }}$ floor, and setting up measuring points for monitoring; removing destroyed outer reinforced concrete, and surface polishing of the steel pipe; repairing the steel plates, crack repairing of steel pipe, and setting up monitoring points on the steel pipe surface; flushing and removing the damaged concrete inside the steel pipes; repairing the reinforcing rebars outside the steel pipe, and injecting concrete; injecting concrete into the steel pipe; outsourcing of the steel pipe; demolishing the temporary support columns; and monitoring the bearing capacity recovery of column 5. For the concrete-encased CFST column, the key mechanisms of column reinforcement with supporting beams include repairing the crack in the steel pipe, replacing the concrete inside the steel pipe, and outsourcing the steel pipe, all of which are outlined in detail in the following:

(1) Repairing Steel Plates and the Crack in the Steel Pipe. The internal steel pipe was severely damaged due to a vertical crack with a length of about $1.50 \mathrm{~m}$ and a maximum width of about $10.0 \mathrm{~mm}$. The outer surface of the steel pipe on both sides of the crack bulged out convexly; the curved surface was also irregular, and the curvature was inconsistent. Therefore, instead of one large steel plate, eight patch-shaped small steel plates, with a length, width, and thickness of about $400 \mathrm{~mm}, 200 \mathrm{~mm}$, and $20 \mathrm{~mm}$, respectively, were used to repair the crack (Figure 4). The outer curvature of the small steel plate was the same as that of the original steel pipe. The inner concave surface of the patch was in contact with the local convex surface of the original steel pipe, and the patch was fitted to the steel pipe surface as good as possible. Therefore, the inner concave shape of each patch was designed using more details and data control. A foursided welded joint was used between the small steel patches and the original steel pipe.

(2) Replacing the Concrete inside the Steel Pipe. The microwound concrete replacement construction was carried out to ensure that the construction process minimized the weakening of the original composite column. This replacement construction was only carried out for column 5 on the $15^{\text {th }}-18^{\text {th }}$ floor.

(a) Concrete flushing and digging: some holes with a diameter of $50 \mathrm{~mm}$ were drilled horizontally at the top and the bottom of the original column. Through the top hole, the damaged concrete inside the steel pipe was flushed by pressurized water injection. Through the bottom hole, the mud, discrete aggregates, slag, etc., generated by the damaged concrete inside the steel pipe were manually dug out. Figure 5 illustrates flushing and digging out the concrete inside the damaged steel pipe of column 5 on the $16^{\text {th }}$ floor. 


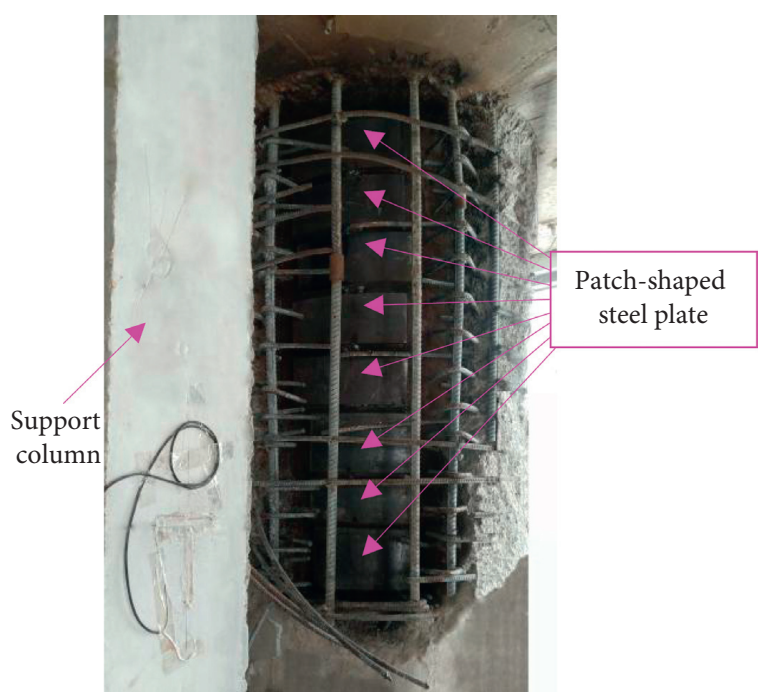

FIGURE 4: Crack repairing of the inner steel pipe.

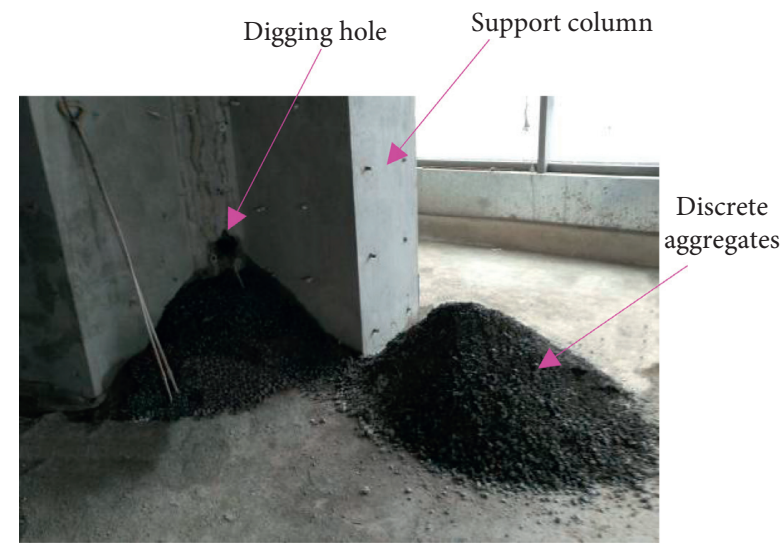

FIGURE 5: Flushing and digging out the concrete inside the damaged steel pipe.

(b) Cleaning the interior resides of the steel pipe: to ensure the effective bonding between the refilled concrete and the old concrete as well as the inner wall of the steel pipe, the slag remaining inside the steel pipe was repeatedly dug out, and the steel pipe was then washed twice with pressurized water.

(c) Accumulated water treatment: since the drainage holes, with a diameter of $50 \mathrm{~mm}$, were drilled horizontally at the bottom of the CFST column, water accumulated in the steel pipe was completely removed by means of external pumping during the cleaning step or before the pressure grouting; the pumping was conducted continuously.

(d) Pressure grouting: the lower digging hole and the drainage hole were sealed, and the top flushing hole was employed to inject the concrete into the steel pipe; sufficient venting holes were also created. The interior of the steel pipe was then densely filled with cement-based concrete. The concrete had a C60 strength grade and should have the following characteristics: no shrinkage, good fluidity, no segregation, and no precipitation. The pressure grouting process was conducted in order from the $15^{\text {th }}$ floor to the $18^{\text {th }}$ floor.

(3) Outsourcing the Steel Pipe. After the above pressure grouting process was completed, the column was subjected to seismic reinforcement by using the outsourcing steel pipe method. The building site is located in an area with a seismic precautionary intensity of $8^{\circ}$. The thickness of the steel pipe is $26 \mathrm{~mm}$, and the top and the bottom of the steel pipe are free and not fixed. After reinforcing the steel pipe, the seismic performance of the column can be improved, which means that the column will have better ductility and energy dissipation capability.

In the above reinforcement project, three key innovative methods were proposed: designing upper and lower corbelshaped temporary support columns, crack repairing the inner steel pipe with patch-shaped steel plates, and replacing the concrete inside the steel pipe.

\section{Monitoring the Reinforcement Construction Process}

In structural reinforcement construction, in order to thoroughly study the load transformation from the supporting columns to the original composite column and the vertical deformation of the structure, a safety monitoring system was established to automatically monitor the stress and the displacement of the main components in real time. Through the WSDQ-wireless strain data acquisition system, the onsite real-time monitoring was started on September 11, 2017, and was completed on February 12, 2018. The monitoring of the reinforcement construction process of column 5 lasted for about two months; we also observed the bearing capacity recovery of column 5 for about three months.

3.1. Arranging Measuring Points. The monitoring of the construction process guarantees us smooth construction onsite and structural safety. The monitoring test has a certain complexity and cannot be repeated due to the influence of the on-site construction. Therefore, the number of monitoring points must be sufficient to ensure data reliability and mutual verification.

The arrangement of the strain measuring points at the temporary support columns of column 5 on the $15^{\text {th }}$ floor is presented in Figure 6(a). Seven strain measuring points were arranged on each support column on the far-side facade and on both left- and right-side facades of the support columns; three measuring points were set up on their concrete surface, i.e., measuring points $1-3$ of the eastern column in Figure 6(a); four measuring points were also considered on the four sides of the reinforcing rebars inside the concrete, i.e., measuring points $4-7$ of the eastern column. No measuring point was set up on the near-side facade of the support columns due to construction reasons. The far- and near-side facades of the support columns were defined by the distance from the 


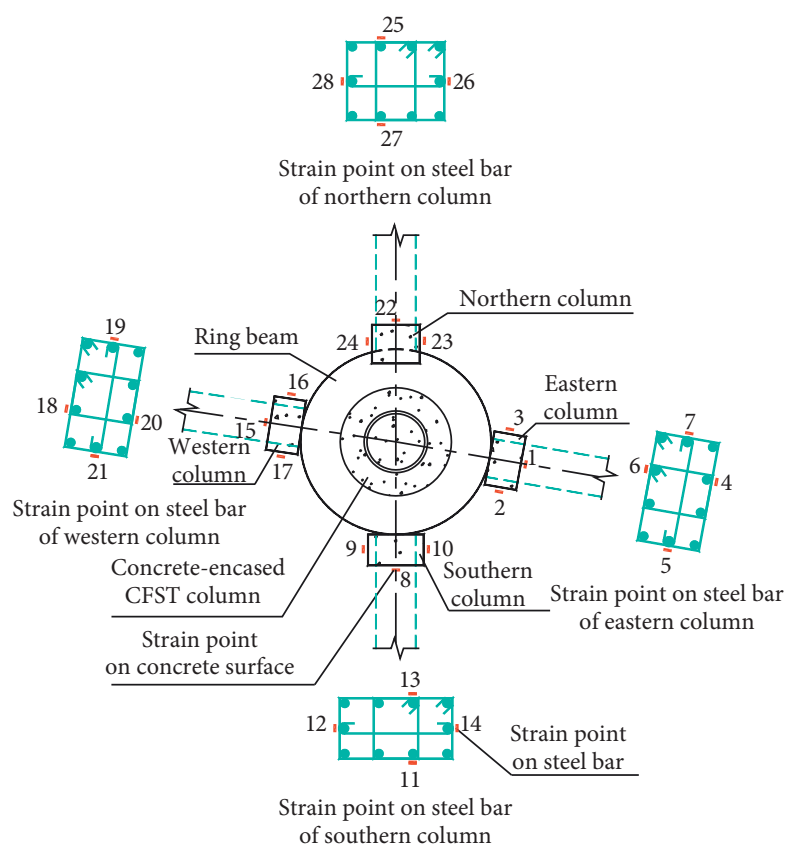

(a)

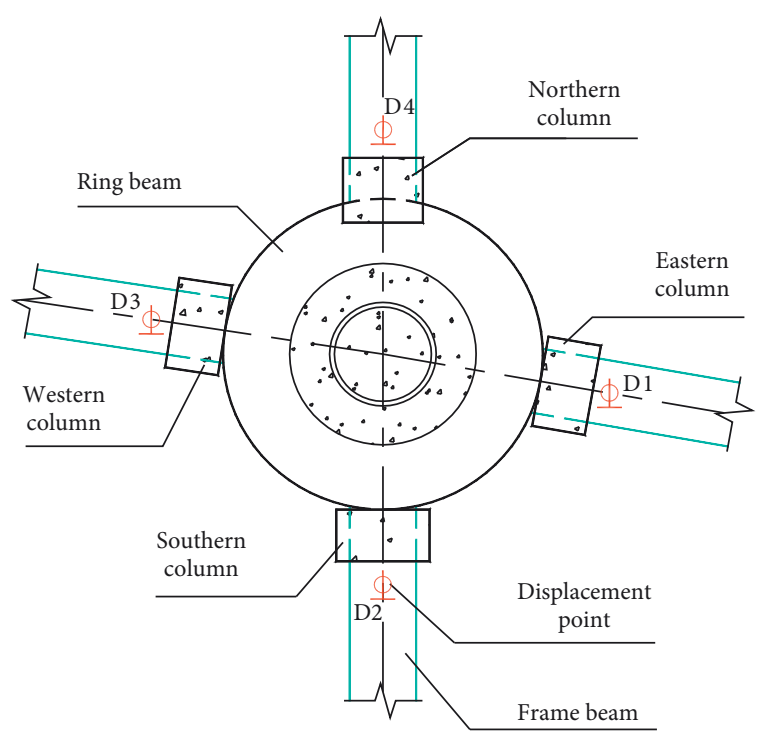

(b)

Figure 6: Strain points of the support columns and the displacement points of beam ends. (a) Arrangement of strain measuring points; (b) arrangement of displacement measuring points.

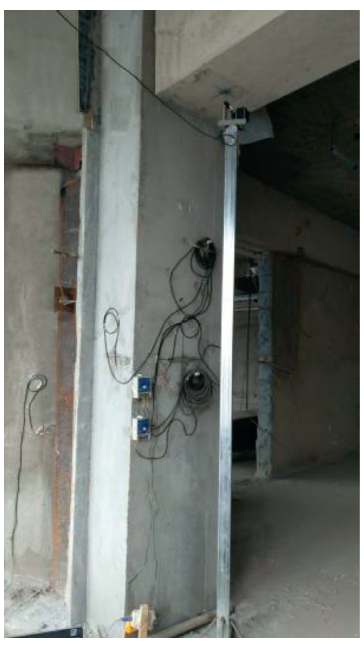

Figure 7: Actual arrangement of strain and displacement measuring points.

original composite column. The steel strain gauge was attached to the partially ground surface of the steel rebar and was protected before pouring concrete. The strain gauge wire was pulled out of the template through a protective sleeve. The strain gauges were all located at the mid-height of the columns. A displacement measuring point was also set up at the ends of four frame beams connected to column 5 on the $15^{\text {th }}$ floor and at the bottom of the frame beams. The specific positions of the displacement measuring points, i.e., D1-D4, are illustrated in Figure 6(b). On the construction site, data acquisition was performed by using a resistance strain displacement meter. The layout of strain and displacement measuring points is depicted in Figure 7.
3.2. Monitoring Stress and Displacement. The reinforcement construction of column 5 began on September 11, 2017, and ended on November 15, 2017. During this process, the vertical displacement and the strain of each measuring point were recorded in real time, and the data were extracted daily at 9: $00 \mathrm{am}$, which lead to the following results. The variations in the vertical displacement of each beam end against time are shown in Figure 8. The stress variations of the east supporting column with time are also displayed in Figure 9. It is obvious that the stress values of measuring points 2 and 3 on the concrete surface are similar to those of measuring points 5 and 7 on the steel pipe, so the stress values of measuring points 3 and 7 are not reported in Figure 9. For the eastern column, the relationship between the stress of the measuring point 6 and the displacement of the 


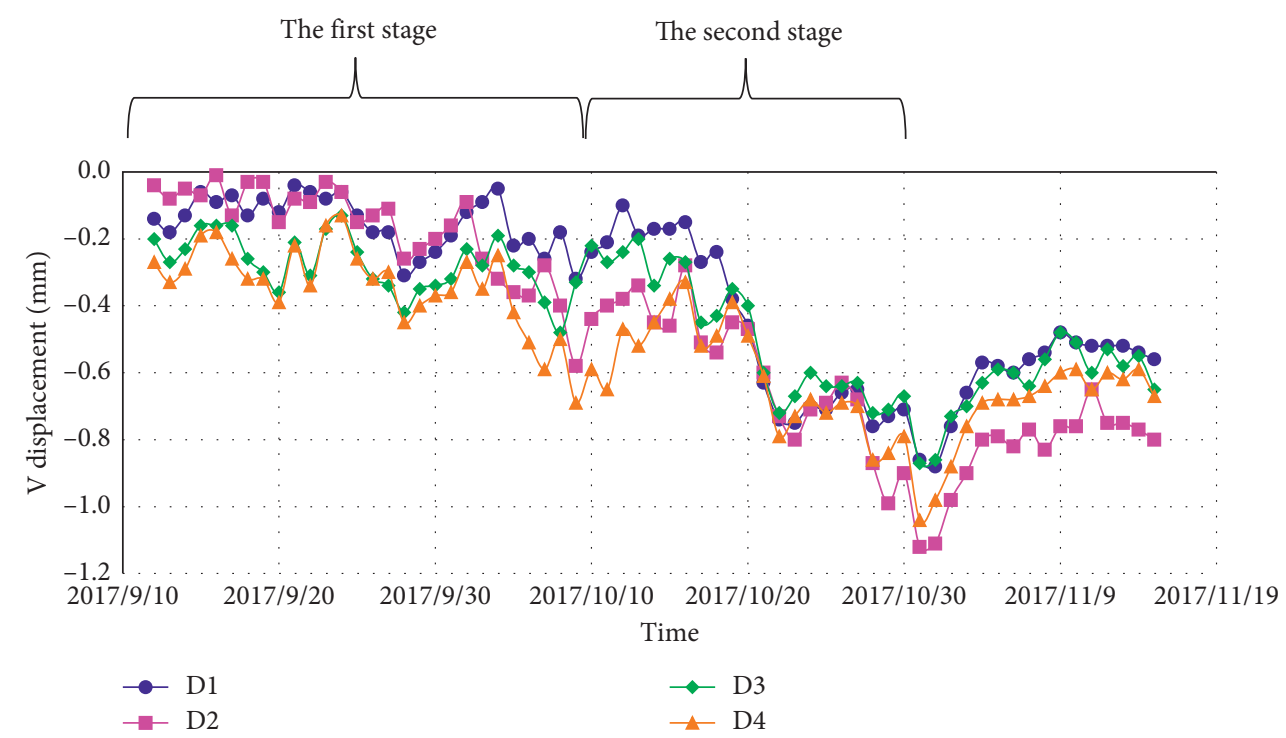

Figure 8: Plot of beam end displacement versus time during construction process.
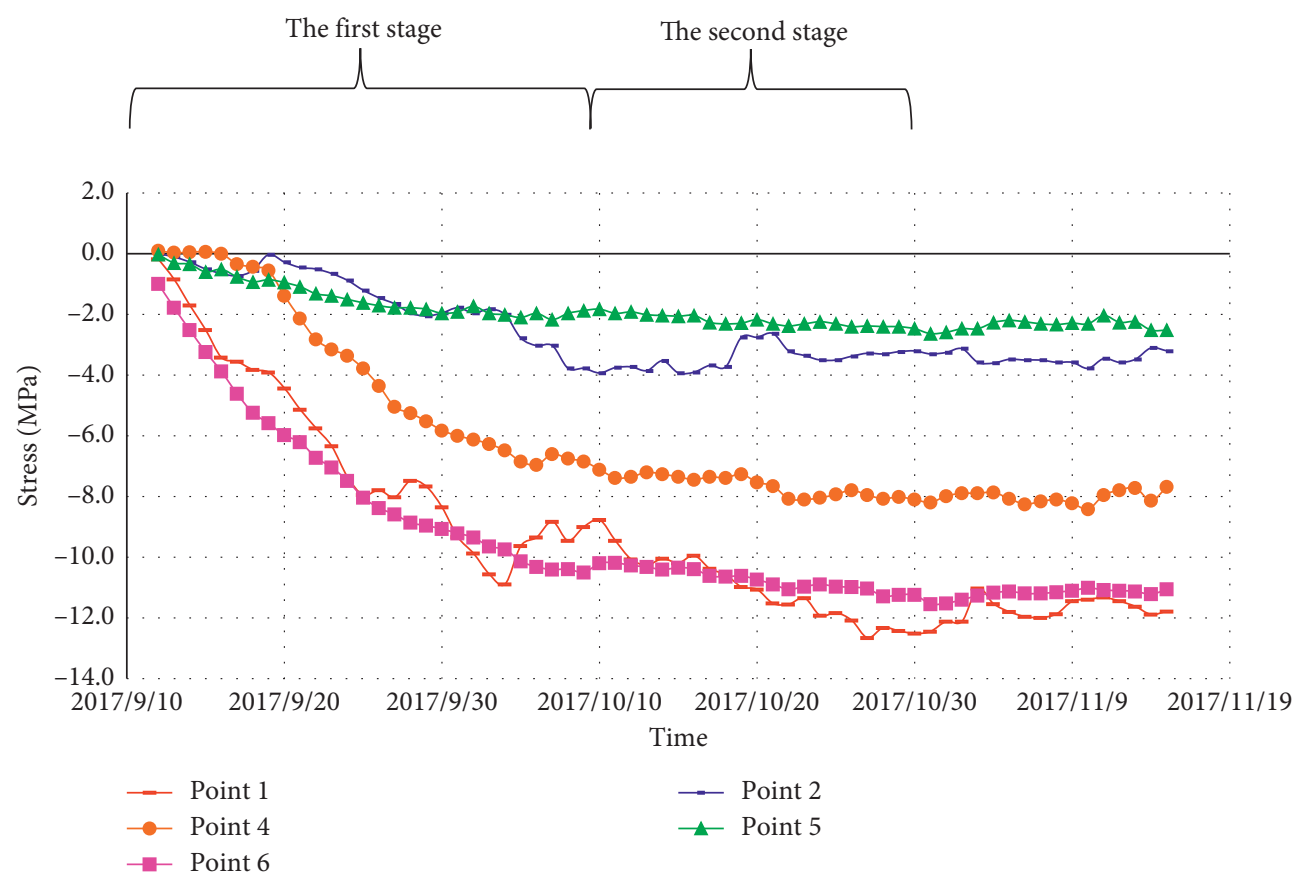

FIGURE 9: Plot of stress versus time of the eastern column during construction process.

beam end is illustrated in Figure 10; the axial force of each supporting column changes with time as presented in Figure 11. Compared to the values at installation time, the stress, stress increment, and axial force values are positive for the tension mode and negative for the compression mode; vertical displacement values are positive for the upward displacement and negative for the downward displacement. In Figure 8, "D1-D4" refer to the number of each displacement measuring point shown in Figure 6(b), and " $V$ displacement" denotes the displacement of each measuring point in the vertical direction. The stress value of each measuring point is calculated by multiplying the monitored strain value by the real-time elastic modulus, $E_{\mathrm{c}}(t)$, of the concrete; $E_{\mathrm{c}}(t)$ is also defined by

$$
\begin{aligned}
& E_{\mathrm{c}}(t)=E_{\mathrm{c} 28} \sqrt{\eta(t)}, \\
& \eta(t)=\exp \left\{s \left[1-\sqrt{\left.\left.\frac{28}{t}\right]\right\}},\right.\right.
\end{aligned}
$$

where $E_{\mathrm{c} 28}$ represents the concrete elastic modulus after 28 days and $s$ stands for the cement type constant $[14,15]$.

According to Figures 8-11, the following findings can be summarized:

(1) The trend of the stress variation of the corresponding measuring points of the four supporting columns 


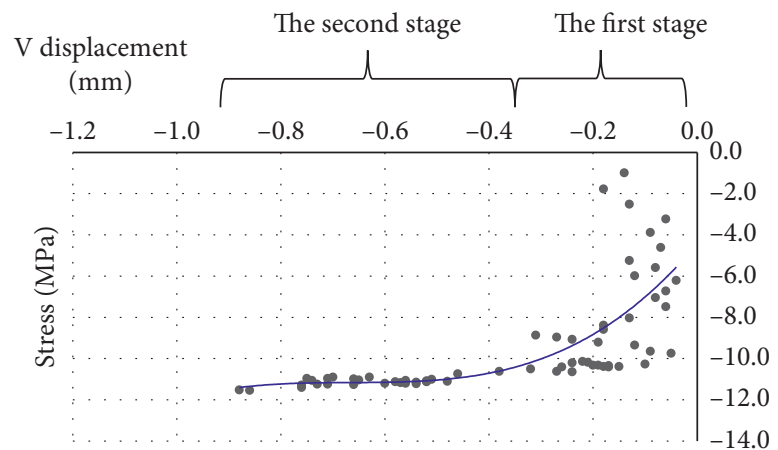

Figure 10: Plot of stress versus beam end displacement of the point 6 on the eastern column.

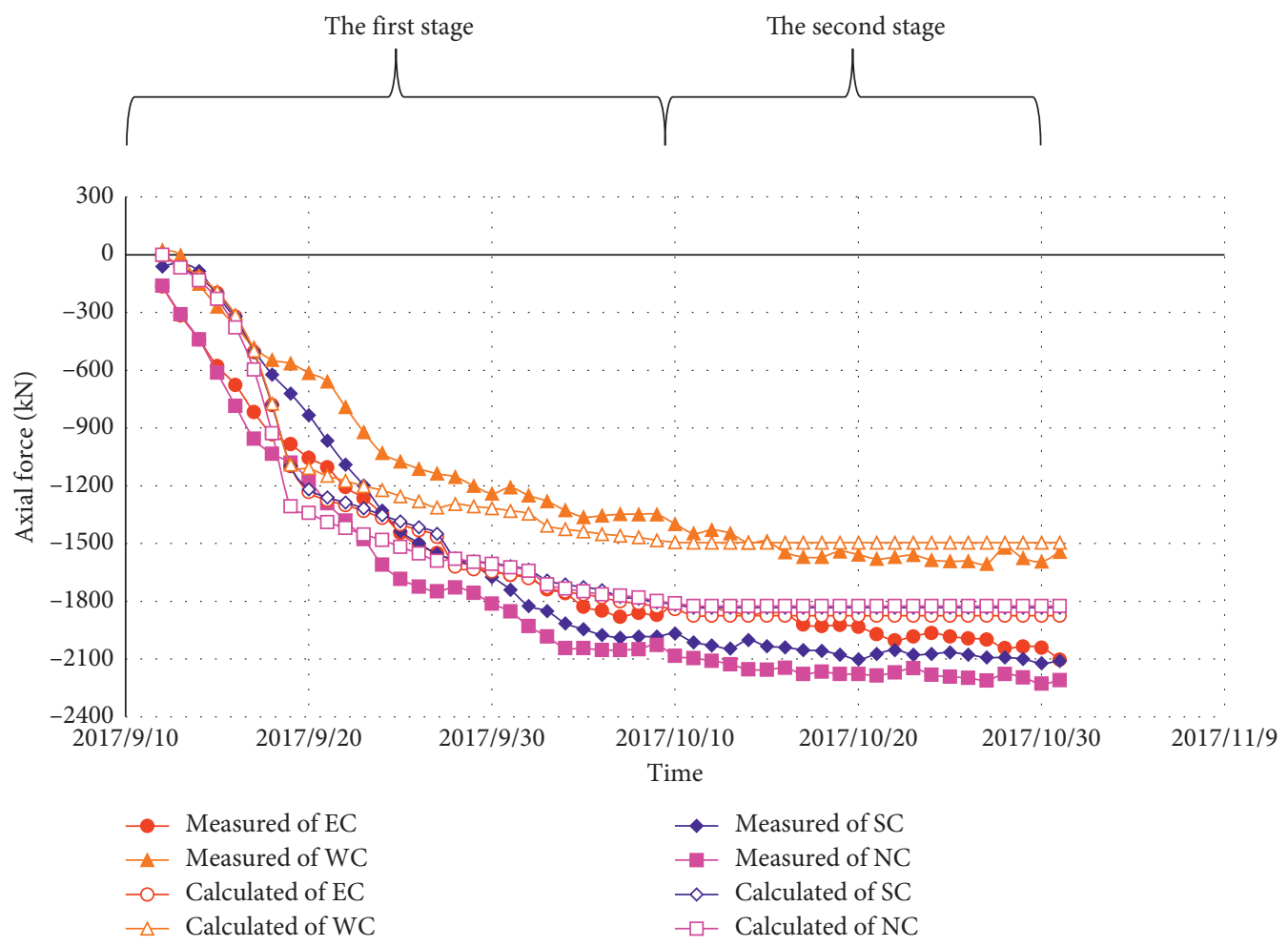

FIgURE 11: Plot of axial force versus time of each support column during construction process.

was the same (Figure 8). At the end of the reinforcement construction stage, the stress values of the reinforcing rebars are tabulated in Table 1 for the eastern, southern, western, and northern support columns.

(2) The stress values of the measuring points of the five steel rebars in the eastern support column were also compared (Figure 9). The stress value of the proximal steel rebar measuring point 6 was the largest, and those of steel rebar measuring points 2 and 5 on both sides were the smallest. These two maximum and minimum values differed greatly, which can be attributed to the fact that the longitudinal rebars in the beam range were anchored by implanting the beam to a depth of $300 \mathrm{~mm}$, while those in the floor range were anchored by the anchor bolt penetrated into the floor. The steel rebars at measuring point 5 were anchored by being penetrated into the floor, whereas the steel rebars at measuring point 6 were anchored to the implanted beam. Therefore, the steel rebars at measuring point 5 were weakly anchored compared to those at measuring point 6 , thereby showing a smaller stress value.

(3) Figure 9 compares measuring point 1 on the concrete surface with steel rebar measuring point 4 in the adjacent concrete cover and contrasts measuring point 2 with measuring point 5 ; it can be seen that the stress values of the measuring points on the concrete surface are larger than those of steel rebar measuring points. The stress values of the concrete surface were also uneven over time, and the curves were not smooth and showed slight variations (Figure 10), 
TABLE 1: Measured and calculated values of beam end displacement, stress, and axial force of the support columns at the end of the construction process.

\begin{tabular}{|c|c|c|c|c|c|c|c|c|c|c|}
\hline \multirow{3}{*}{ Column } & \multirow{2}{*}{\multicolumn{2}{|c|}{ Displacement $(\mathrm{mm})$}} & \multicolumn{6}{|c|}{ Stress $(\mathrm{MPa})$} & \multirow{2}{*}{\multicolumn{2}{|c|}{ Axial force $(\mathrm{kN})$}} \\
\hline & & & & Near sic & & & Far sid & & & \\
\hline & Measured & Calculated & Point & Measured & Calculated & Point & Measured & Calculated & Measured & Calculated \\
\hline East & -0.86 & -0.86 & 6 & -11.54 & -9.30 & 4 & -8.19 & -6.51 & -2103.0 & -1875.0 \\
\hline South & -1.12 & -0.83 & 13 & -12.21 & -9.09 & 11 & -8.01 & -6.34 & -2109.0 & -1833.0 \\
\hline West & -0.87 & -0.63 & 20 & -8.64 & -7.42 & 18 & -5.17 & -4.94 & -1544.0 & -1495.0 \\
\hline North & -1.04 & -0.69 & 27 & -10.27 & -8.45 & 25 & -6.73 & -4.43 & -2210.0 & -1824.0 \\
\hline
\end{tabular}

which can be owing to the fact that the measuring points of the concrete surface were set up ten days after pouring concrete of the supporting columns; indeed, compared with the internal steel rebars, the shrinkage of the concrete surface is larger, and the concrete surface measuring points are significantly affected by external interference factors.

(4) According to Figure 10, the relationship between the stress $(\sigma)$ of steel rebar measuring point 6 on the eastern column and the vertical displacement $\left(\Delta_{z}\right)$ of the beam end can be expressed by

$$
\sigma=22.553 \Delta_{z}^{3}+45.074 \Delta_{z}^{2}+30.135 \Delta_{Z}-4.424 .
$$

3.3. Numerical Simulation. The loading and unloading process between the temporary column support and the main structure is a transformation process of complex mechanical states as well as a process of gradual transfer of structural mechanics and redistribution of internal forces. As a stand-alone system, when the temporary support columns interact with the main structure, the local failure range of the original main structural component develops continuously, and the supporting internal force is also constantly changing, so the simulation of the load conversion process of temporary support is a type of static, nonlinear analysis, which is a slow time-dependent mechanics problem $[16,17]$. Based on this theory, the key techniques and methods such as element life and death technology, step loading, and unit grouping were used to numerically simulate the time-varying effect during structural construction numerically $[18,19]$. The structural reinforcement construction process was divided into a series of construction balanced stages $[20,21]$. Moreover, by means of the finite element continuous solution to each stage, the numerical simulation method for the load conversion process of the temporary support was developed.

By employing ANSYS finite element analysis software, the reinforcement construction process of column 5 on the $15^{\text {th }}$ floor, or rather, the load conversion process of the temporary support columns, was numerically simulated. The finite element model developed is presented in Figure 12. In this model, the SOLID185 unit was used for concrete, and the SHELL181 unit was applied to the steel tube. The column base and the distal ends of the eastern, southern, and western frame beams were fixed, but the distal end of the northern frame beam was free. The construction process was

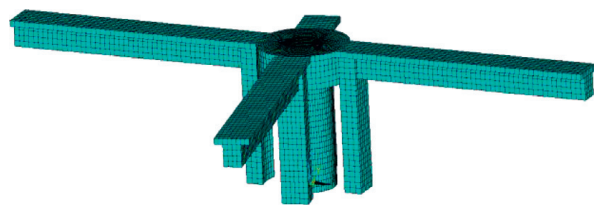

FIgURE 12: Finite element model of column 5 on the $15^{\text {th }}$ floor.

simulated as a static nonlinear analysis. At each construction stage, the structural members were in an elastic phase, and the materials were assumed elastic. During the simulation analysis, it was observed that the original composite column 5 had some defects and its range was gradually expanded, causing the vertical downward displacement of the free beam end to gradually increase. The temporary support columns gradually played a supporting role in preventing the beam end displacement from developing downward. Therefore, the axial pressure on the support columns gradually increased. However, the degree of the defects in the original column was not a quantitative value. Therefore, when the calculated displacement of the east beam end was equal to the measured value of $-0.86 \mathrm{~mm}$ at the end of the construction phase, it was used as the simulated target displacement, and the following numerical simulation was then performed. The numerical simulation process of the reinforcement construction for column 5 is shown in Figure 13.

(1) Temporary jacking steel columns that were removed before the temporary reinforced concrete support columns began to work are not considered in the simulation. Under the action of $20 \%$ of the vertical standard load of the original composite column, i.e., $20 \% \times 12,230=2,446 \mathrm{kN}$, the element life and death technology were used to give death to $50 \%$ of the concrete elements inside the steel pipe and those of the four supporting columns. And the elements of the central destruction part of the original column were given death, as shown in Figure 13(a). The central destruction part refers to the part of the inner steel pipe and the outer reinforced concrete in the elevation range of $1.45 \mathrm{~m}-2.03 \mathrm{~m}$ and in a horizontal angle range of $302^{\circ}-328^{\circ}$. The angle is defined as described above: the south direction is $270^{\circ}$, and the east direction is $360^{\circ}$. The load was only shared by the steel pipe and the outer reinforced concrete, and the calculation results were considered as the initial stress state of the following step. 


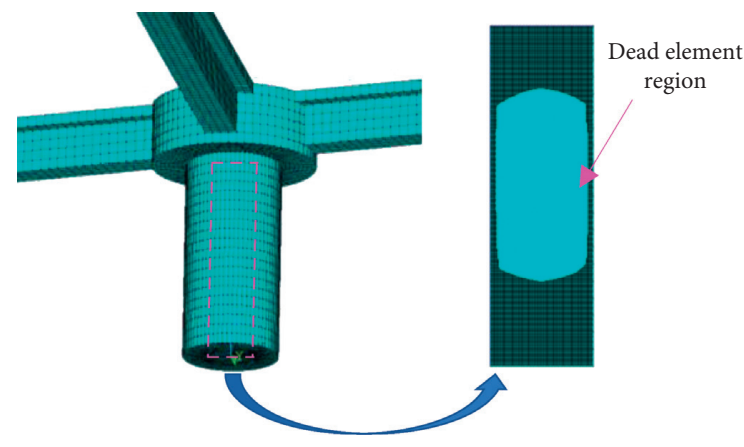

(1) The failure location of concrete inside the steel pipe at the center longitudinal section

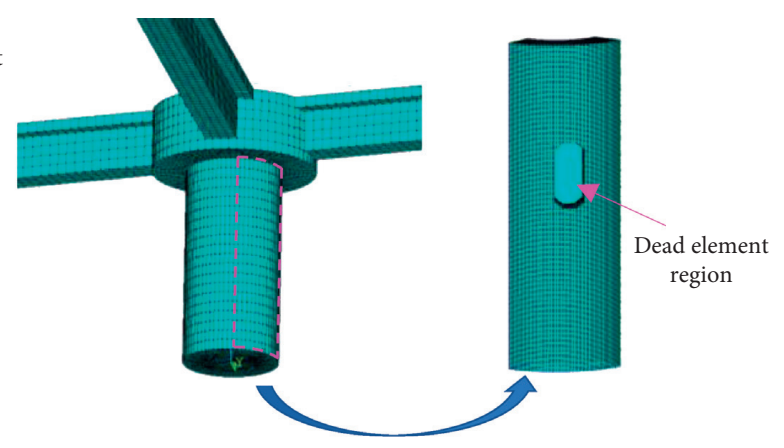

(2) The central destruction part of the steel pipe and the outer reinforced concrete

(a)

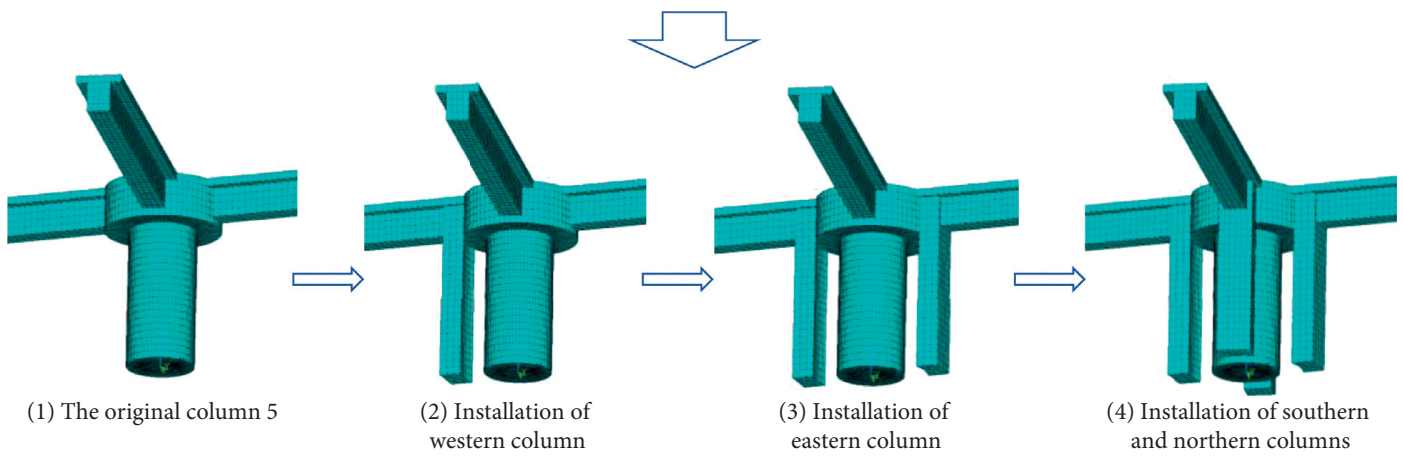

(b)

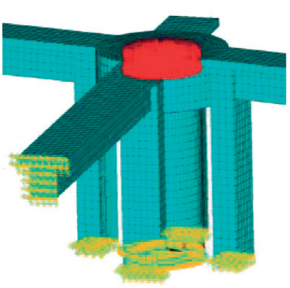

(1) The calculation model

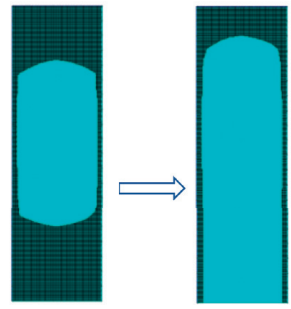

(2) The step-by-step simulation of the failure expansion process of the inner concrete

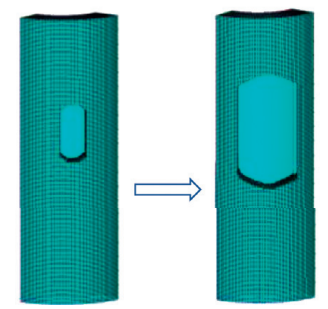

(3) The step-by-step simulation of the failure expansion process of the steel pipe and the outer reinforced concrete

(c)
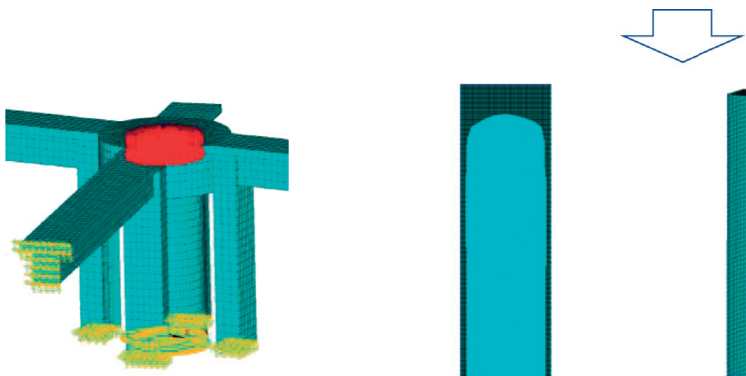

(1) The calculation model

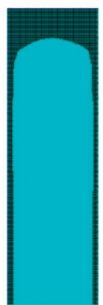

(2) The failure state of the inner concrete

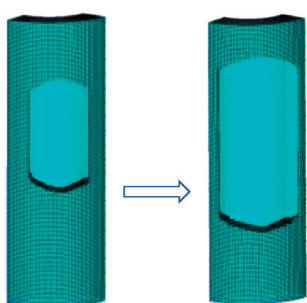

(3) The step-by-step simulation of the failure expansion process of the steel pipe and the outer reinforced concrete

(d)

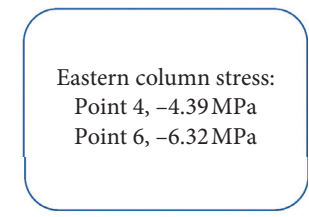

(4) Simulation results of eastern column stress

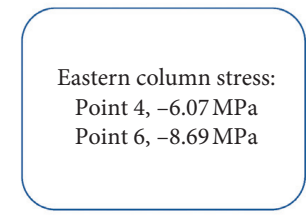
(4) Simulation results of eastern column stress

FIgURE 13: The numerical simulation process of the reinforcement construction for column 5. 
(2) Under the effect of all the standard vertical loads, i.e., $12,230 \mathrm{kN}$, the elements of the four supporting columns were given birth, and the elements of the central destruction part of the original column were kept to be death, as shown in Figures 13(a) and 13(b). The load was shared by the remaining intact part of the inner steel pipe, the outer concrete, and the four supporting columns. The continuous calculation was then performed.

(3) Based on the second step, the failure elements of the concrete inside the steel pipe gradually developed from $50 \%$ to $85 \%$; the destruction range of the central destruction part was gradually expanded along the upper and lower sides as well as the horizontal sides. In other words, the range of the failure elements, which are given death, was gradually extended, as shown in Figures 13(c) and 13(d). Each step on the upper and lower sides was expanded by $0.145 \mathrm{~m}$, and each step on the horizontal side was extended by $8^{\circ}$. Step-by-step calculation and continuous solution were performed in the simulation. Finally, the destruction of the inner steel pipe and the outer reinforced concrete in the original column ranges from the elevation of $0.73 \mathrm{~m}$ to $2.61 \mathrm{~m}$ and the horizontal angle of $270^{\circ}$ to $360^{\circ}$.

At the end of the reinforcement construction phase (October 31, 2017), the comparison between the simulated and the measured values of the maximum displacement of the beam end, the maximum stress, and the axial force of the support columns are presented in Table 1. The stress analysis of the support columns is also illustrated in Figure 14. The steel rebar stress simulation and the actual measurement of measuring points 6 and 4 on the eastern column are displayed in Figure 15. Figure 11 also compares the simulated and measured values of the axial forces of the four supporting columns.

\subsection{Monitoring Data Analysis}

(1) By monitoring data analysis, the reinforcement construction process was divided into two phases, and the time ranges of each phase are outlined in Figures 8-11.

The construction steps completed in the first stage (September 11, 2017, to October 9, 2017) were crack repairing steel pipe in column 5; flushing and digging out concrete damaged inside the steel pipe of column 5 on the $16^{\text {th }}$ to $18^{\text {th }}$ floor; and repairing steel rebars and recasting outer concrete. The displacement curves of the beam ends decreased slowly and uniformly at the first stage, and the four displacement values were similar (Figure 8). The stress of measuring points 4 and 6 increased sharply at the first stage, and the slope of the stress-time curve was large; the stress value changed evenly (Figure 9). The axial forces of the four support columns varied uniformly, and the axial force of each column continued to increase daily; the slope of axial force versus time curve was large for each column (Figure 11).
The construction steps completed in the second stage (October 9, 2017, to October 31, 2017) were flushing and digging out concrete damaged inside the steel pipe of column 5 on the $15^{\text {th }}$ floor; pressure grouting of the steel pipe of column 5; outsourcing the steel pipe of column 5 on the $15^{\text {th }}$ floor; and removing the temporary support columns of column 5 on the $18^{\text {th }}$ floor. In this stage, the displacement of the beam ends dropped rapidly, and the slope of the curves was larger than that of the curves at the first stage; the displacement value changed steadily, and the four displacement values were similar (Figure 8). The stress growth of measuring points 4 and 6 were slow at the second stage, the stress-time curve tended to be horizontal, and the stress value changed regularly (Figure 9). The axial force of the four support columns rose slowly, the axial force versus time curve gradually tended to be horizontal, and the axial force value was stable (Figure 11).

From October 31, 2017, to November 15, 2017, the support columns of each layer were successively removed, and the displacements of the beam end increased to a small extent.

(2) The load conversion of the temporary support columns lasted for a long time, about 50 days. At the first stage, the support columns were subjected to the converted load, and the axial compression deformation of the lower half of the columns was larger than that of the upper half, which contributed substantially to the vertical displacement of the beam end. The compressive stress at the strain point at the mid-height of the columns continued to rise and reached a certain large value (Figure 10); the first stage lasted for 30 days. At the second stage, the support columns continued to bear the load, and the compressive stress grew slowly at the strain point and tended to be stable. The axial compression deformation of the upper half of the columns was larger than that of the lower half, which contributed significantly to the vertical displacement of the beam end; the second stage lasted for 20 days. This process is a reasonable interpretation of the theory of slow time-dependent structural mechanics.

(3) The numerical simulation agrees well with the actual monitoring data. According to the data tabulated in Table 1, at the end of the second stage, the maximum vertical displacement of the beam end was $1.12 \mathrm{~mm}$, and the sum of the axial forces of the four support columns of column 5 on the $15^{\text {th }}$ floor was $7,966.0 \mathrm{kN}$, accounting for $65 \%$ of the standard load of $12,230.0 \mathrm{kN}$. In accordance with the simulation data, the sum of the axial forces of the four support columns was $7,027.0 \mathrm{kN}$, accounting for $57 \%$ of the standard load. By utilizing the monitoring data and numerical simulation analysis, the partial load conversion of the temporary support columns, i.e., the partial unloading process of the original composite column, met the 


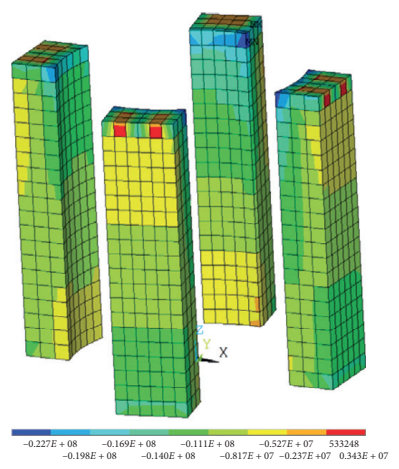

FIgURE 14: Stress analysis of support columns at the end of the construction process.

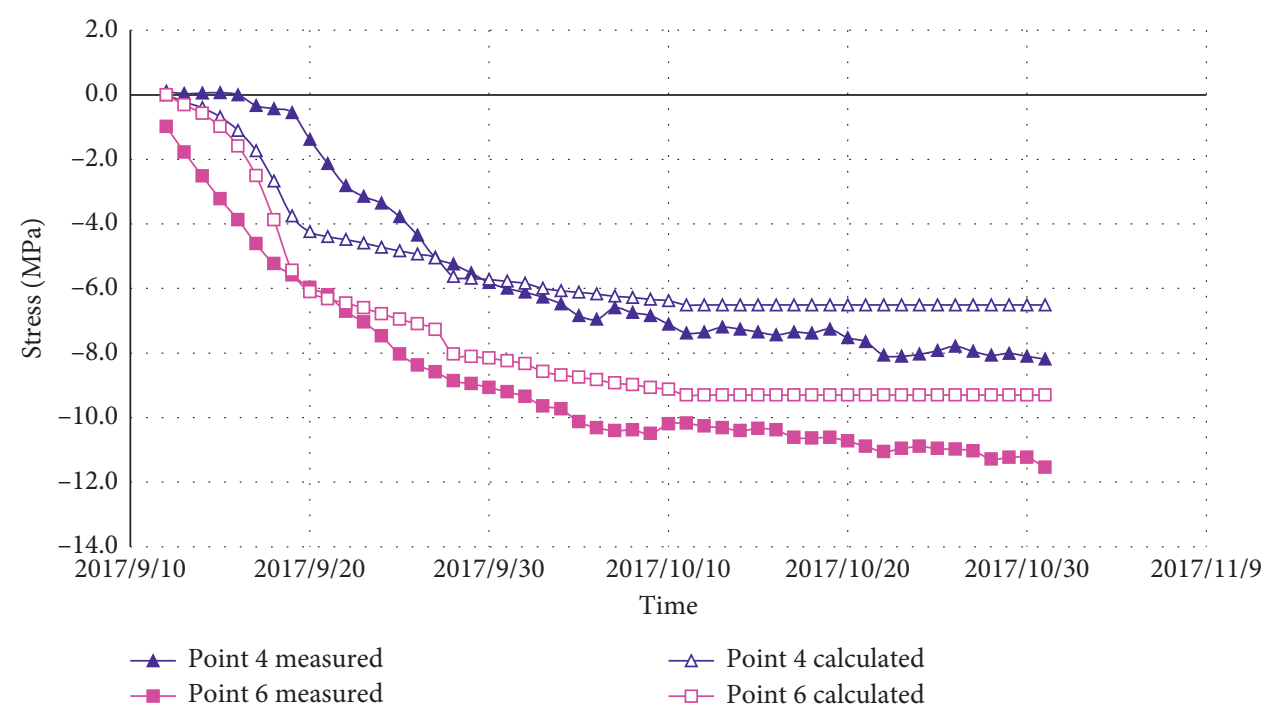

Figure 15: Stress simulation and measurement of measuring points 4 and 6 on the eastern column.

design requirements, and the structural components were safe and reliable during the reinforcement construction process of column 5 .

\section{Monitoring the Process of Bearing Capacity Recovery}

The safety monitoring stage of the progress of bearing capacity recovery of column 5 on the $15^{\text {th }}$ floor lasted for about three months, from November 16, 2017, to February 12, 2018.

4.1. Arranging Measuring Points. In order to monitor the bearing capacity recovery of column 5 on the $15^{\text {th }}$ floor, prior to repairing concrete and encasing the steel pipe in reinforced concrete, on October 12, 2017, three strain measuring points (29-31) were set up on the inner steel pipe, and three strain measuring points (32-34) were arranged on the longitudinal rebars of the outer reinforced concrete. This specific arrangement is illustrated in Figures 16 and 17. The four displacement measuring points D1-D4 continued monitoring work, and their data were continuous with that of the above reinforcement construction stage.
4.2. Monitoring Results and Numerical Simulation. In the stage of bearing capacity recovery of column 5 on the $15^{\text {th }}$ floor, the vertical displacement of the beam end and the strain of the measuring points were monitored in real time. The data were extracted from all real-time data at 9:00 am every other day, and the displacement and strain monitoring results of each measuring point were obtained. At this stage, the displacement values of the beam ends were continuous with the values of the reinforcement construction stage (Figure 8). These specific data are shown in Figure 18; the strain value on the date of installation, i.e., October 12, 2017, is zero. According to the strain monitoring, the increment of stress in the $z$ direction of each measuring point on the steel pipe and the steel rebars of the outer reinforced concrete is delineated in Figure 19.

The numerical simulation of the bearing capacity recovery of column 5 was carried out by using the finite element model presented in Figure 12. Table 2 compares the calculated results and the actual measured data.

(1) During the stage of bearing capacity recovery of column 5, the displacement value of each beam end was basically stable, and the values of the eastern displacement, southern displacement, western 


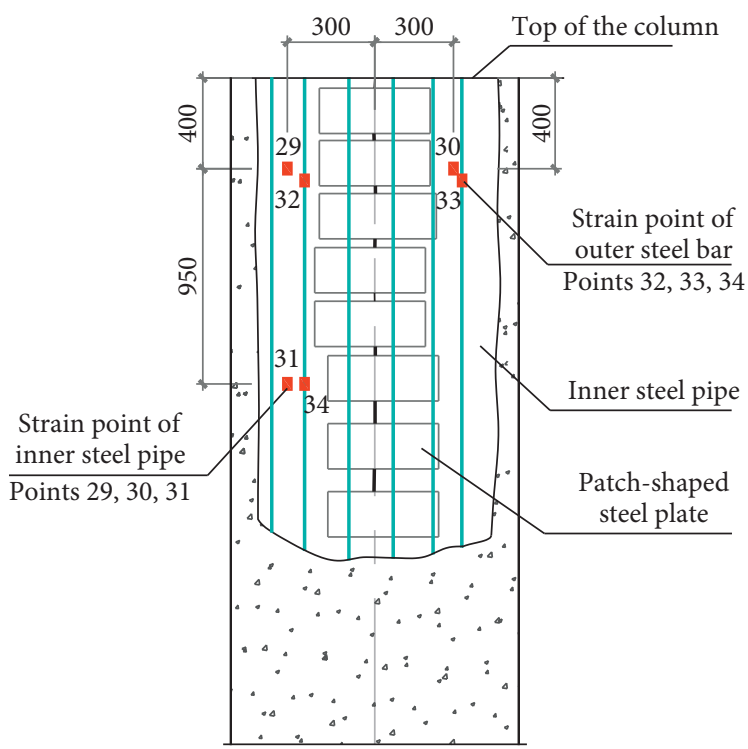

FIGURE 16: Strain point of the inner steel pipe and the outer steel rebars during the process of bearing capacity recovery.

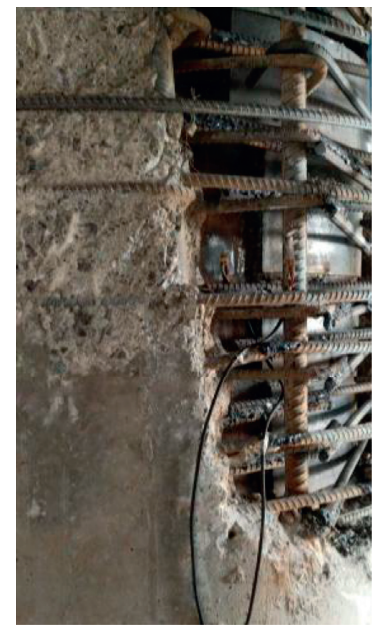

Figure 17: Actual arrangements of strain measuring points 31 and 34.

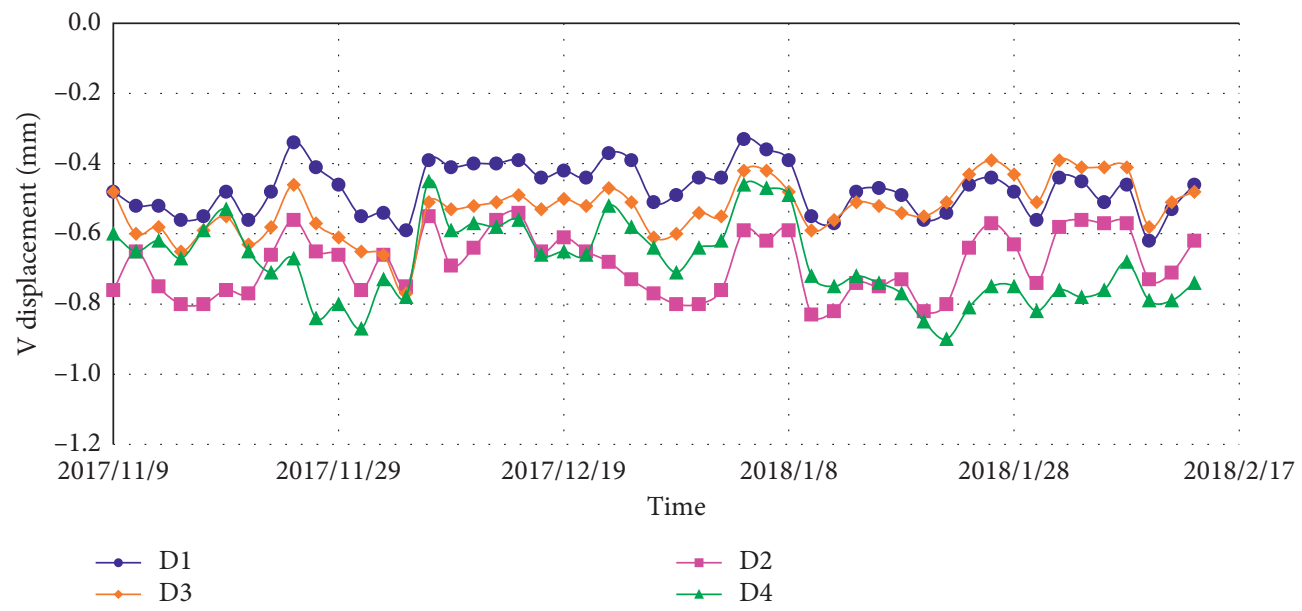

FiguRe 18: Plot of beam end displacement versus time during the process of bearing capacity recovery. 


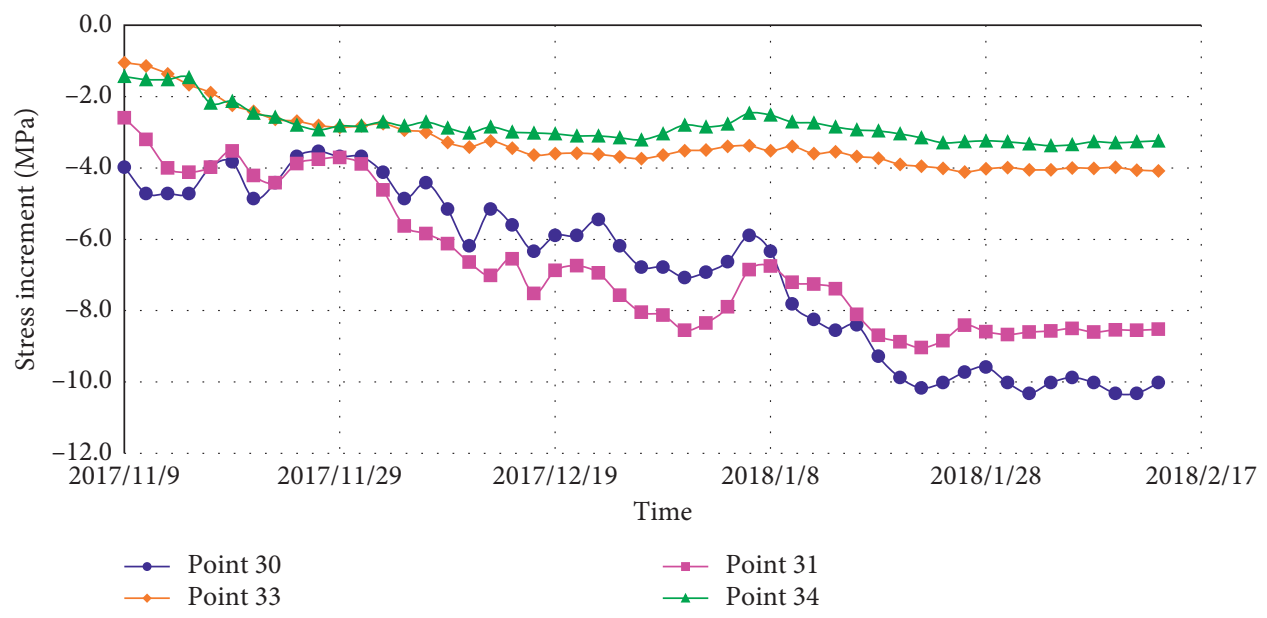

FIGURE 19: Stress increment in the $z$ direction of each measuring point during the process of bearing capacity recovery.

TABle 2: Measured and calculated values of an increment in the stress of column 5 during the process of bearing capacity recovery.

\begin{tabular}{lccc}
\hline Measuring point & \multicolumn{3}{c}{$\begin{array}{c}\text { Increment in stress } \\
(\mathrm{MPa})\end{array}$} \\
& \multicolumn{3}{c}{ Measured } \\
& 30 & -10.02 & -7.52 \\
Inner steel pipe & 31 & -8.52 & -7.53 \\
Steel rebars of the outer reinforced & 33 & -4.08 & -7.65 \\
concrete & 34 & -3.24 & -7.53 \\
\hline
\end{tabular}

displacement, and northern displacement ranged from $-0.62 \mathrm{~mm}$ to $-0.33 \mathrm{~mm}$, from $-0.83 \mathrm{~mm}$ to $-0.54 \mathrm{~mm}$, from $-0.77 \mathrm{~mm}$ to $-0.39 \mathrm{~mm}$, and from $-0.90 \mathrm{~mm}$ to $-0.45 \mathrm{~mm}$, respectively; the displacement variation trend of the beam end was relatively uniform (Figure 18). The displacement value was also reduced compared to the value obtained before the support columns were removed.

(2) Since the temporary support columns were demolished on November 15, 2017, the increment in the stress of each measuring point on the inner steel pipe and on the steel rebars of the outer reinforced concrete gradually increased, and the trend gradually stabilized after January 18, 2018. After about one month of stabilization, the monitoring work was stopped on February 12, 2018. The measured values and the simulated values of the increment in stress increments were within the reasonable range of the design.

(3) The duration of the process of bearing capacity recovery of column 5 was about 60 days and can be categorized as a process of slow time-dependent structural mechanics. Moreover, the bearing capacity recovery of column 5 satisfied the design requirements. Finally, during this process, the structural components were safe and reliable.

\section{Conclusions}

(1) In the frame-core wall structure, with the reinforcement project of a heavy-duty concrete-encased CFST column as the background, the mechanism of column reinforcement with supporting beams was proposed. The key mechanisms include designing the upper and lower corbel-shaped temporary support columns, crack repairing the inner steel pipe using patch-shaped steel plates, and replacing concrete inside the steel pipe. These key mechanisms are advanced, innovative, and effective and can be extended to the reinforcement construction of similar large structures. The established system for monitoring reinforcement construction and bearing capacity recovery of CFST columns has excellent stability, durability, and extensibility, provides the structural load conversion history as well as stress and displacement monitoring data, and collects valuable measurement data.

(2) Based on the theory of slow time-dependent mechanics, monitoring the safety of the construction process of column 5 reveals the following information: the load conversion process of the temporary support column was divided into two stages. At the first stage, lasting for 30 days, the displacement of the beam end decreased slowly, but the stress on the support columns increased rapidly. At the second stage, lasting for 20 days, the displacement of the beam end dropped rapidly, but the stress on the support columns rose slowly. At the first stage, the axial compression deformation of the lower half of the column was larger than that of the upper half, which contributed a large amount to the vertical displacement of the beam end. At the second stage, the axial compression deformation of the upper half of the column contributed considerably to the vertical displacement of the beam end. 
At the end of the reinforcement construction stage, the maximum vertical displacement of the beam end was $1.12 \mathrm{~mm}$, and the sum of the axial forces of the four supporting columns of column 5 on the $15^{\text {th }}$ floor was $7,966.0 \mathrm{kN}$, accounting for $65 \%$ of the standard load of $12,230.0 \mathrm{kN}$. The simulation calculated the sum of the axial forces of the four support columns as $7,027.0 \mathrm{kN}$, accounting for $57 \%$ of the standard load. Therefore, the load conversion process of the temporary support columns fulfilled the design requirements, and the structural components were safe and reliable during the reinforcement construction of column 5 .

(3) Monitoring the bearing capacity recovery of column 5 reveals that the vertical displacement value of each beam end was stable during the recovery process and that the displacement value was reduced compared to its value before the support columns were removed. Moreover, since the temporary support columns were completely demolished, the increment in the stress of each measuring point on the inner steel pipe and the steel rebars of the outer reinforced concrete gradually increased, and the value tended to become stable after about 60 days. The bearing capacity recovery of column 5 met the design requirements, and during this process, the structural components were safe and reliable.

(4) The simulation data on the reinforcement construction is in agreement with the field test results, which proves that the construction simulation developed based on the theory of slow time-varying mechanics and the method of static nonlinear analysis is accurate and effective. Through the simulation and construction monitoring, the mechanical behavior and deformation rule of the structure during construction and service can effectively be obtained, which provides theoretical and measured data for structural safety assurance, evaluation, and rational use, and have the essential reference value for similar projects.

\section{Data Availability}

The data used to support the findings of this study are included within the article.

\section{Conflicts of Interest}

The authors declare no potential conflicts of interest with respect to the research, authorship, and/or publication of this article.

\section{Acknowledgments}

This work was finically supported by the National Natural Science Foundation of China (Grant no. 51578357), the Shanxi Provincial Natural Science Foundation of China (2015011062), and the Supporting Project for Scientific
Research Activities of Overseas Students in Shanxi Province (DC1900000602). The support is sincerely appreciated.

\section{References}

[1] X. Wu, Q. Yu, and Y. G. Huang, "Effect of preload on the axial capacity of CFST reinforced concrete columns," Journal of Tsinghua University (Science and Technology), vol. 54, no. 5, pp. 556-562, 2014, in Chinese.

[2] W. Qian, W. Li, L.-h. Han, and X.-l. Zhao, "Analytical behavior of concrete-encased concrete-filled steel tubular column to steel beam joints with RC slabs," Engineering Mechanics, vol. 33, pp. 95-100, 2016, in Chinese.

[3] Pavel Ryjáček and M. Vokáč, "Long-term monitoring of steel railway bridge interaction with continuous welded rail," Journal of Constructional Steel Research, vol. 99, pp. 176-186, 2014.

[4] Y. F. Luo, Z. W. Ye, X. N. Guo, X. H. Qiang, and X. M. Chen, "Data missing mechanism and missing data real-time processing methods in the construction monitoring of steel structures," Advances in Structural Engineering, vol. 18, no. 4, pp. 585-601, 2015.

[5] Y.-F. An and L.-H. Han, "Behaviour of concrete-encased CFST columns under combined compression and bending," Journal of Constructional Steel Research, vol. 101, pp. 314-330, 2014.

[6] Q.-X. Ren, L.-H. Han, C. Hou, Z. Tao, and S. Li, "Concreteencased CFST columns under combined compression and torsion: experimental investigation," Journal of Constructional Steel Research, vol. 138, pp. 729-741, 2017.

[7] Q. Wang, "Analysis and discussion on the reinforcement treatment technology of frost-cracking concrete-filled steel tubular columns," Steel Construction, vol. 8, no. 30, pp. 68-71, 2015, in Chinese.

[8] M.-S. Yuan, L. Li-Xun, Y. Cheng et al., "Replacement and strengthening of concrete filled steel tube column in some super high-rise building," Construction Technology, vol. 43, no. 10, pp. 46-49, 2014, in Chinese.

[9] B. Song, H. N. Li, L. Ren, and S. L. Fan, "Structural health monitoring and analyzing for the whole high temperature cutting process of a steel beam," Engineering Mechanics, vol. 33, no. 9, pp. 69-75, 2016, in Chinese.

[10] Q. Yang, Shao-Le Yu, X. W. Zhang et al., "The construction technology of roof steel structure in YanCheng NanYang airport," Advances in Civil Engineering, vol. 2018, Article ID 6386020, 12 pages, 2018.

[11] G. Xu, J. Zhang, H. Liu, C Ren, and ., "Shanghai center project excavation induced ground surface movements and deformations," Frontiers of Structural and Civil Engineering, vol. 12, no. 1, pp. 26-43, 2018.

[12] H.-B. Xiong, J. X. Cao, and F. L. Zhang, "Displacement monitoring method for frame tube structure with strengthened stories," Journal of Zhejiang University (Engineering Science), vol. 50, no. 9, pp. 1752-1760, 2016, in Chinese.

[13] J. Su, Y. Xia, Y. Xu, X. Zhao, and Q. Zhang, "Settlement monitoring of a supertall building using the Kalman filtering technique and forward construction stage analysis," Advances in Structural Engineering, vol. 17, no. 6, pp. 881-893, 2014.

[14] H.-J. Wang, Analysis and control of time-dependent behavior of high-rise and large span structures in construction,Ph.D. thesis, Harbin Institute of Technology Harbin, China, in Chinese, 2012.

[15] H. J. Wang, H. L. Qian, F. Fan, X. Zhi, and J. Lu, "Tracking investigation of whole construction process of Kingkey 
financial centre," Journal of Harbin Institute of Technology, vol. 47, no. 6, pp. 15-20, 2015, in Chinese.

[16] G.-Y. Wang, "On mechanics of time-varying structures," China Civil Engineering Journal, vol. 33, no. 6, pp. 105-108, 2000, in Chinese.

[17] X.-Y. Qi, X. Zhao, P. P. Zhang, J. Ding, and S. Chao, "Effect analysis of deformation difference between vertical members of the Shanghai Tower," Journal of Building Structures, vol. 32, no. 7, pp. 15-21, 2011, in Chinese.

[18] Z. Jiang, H.-P. Ge, X.-T. Wang, Z. He, and Y. Luo, "A method of element birth and death of local configuration constraint and its application in construction mechanics," Journal of Building Structures, vol. 33, no. 8, pp. 101-108, 2012, in Chinese.

[19] G. Yan-Lin and L. Xue-Wu, "State nonlinear finite element method for construction mechanics analysis of steel structures," Engineering Mechanics, vol. 25, no. 10, pp. 19-24, 2008, in Chinese.

[20] M. Z. Diao, Y. Li, W.-m. Yan, X.-w. Cheng, and D.-y. Li, "Numerical analysis of construction process of large-span half steel plate reinforced concrete roof," Engineering Mechanics, vol. 32, pp. 240-247, 2015, in Chinese.

[21] Z. Ye, Y.-F. Luo, X.-m. Chen, and B. Jia, "Improved method of step by step modelling and its application in construction simulation," Journal of Tongji University (Natural Science), vol. 44 , no. 1 , pp. $73-80,2016$, in Chinese. 